\title{
Characterization of clay filled poly (butylene terephthalate) nanocomposites prepared by solution blending
}

\author{
Khalid Saeed $^{1 *}$ and Inayatullah Khan ${ }^{1}$ \\ 'Department of Chemistry, University of Malakand, Chakdara, Dir (Lower), Khyber Pakhtunkhwa, Pakistan \\ *khalidkhalil2002@yahoo.com
}

\begin{abstract}
Kaolin clay/poly (butylene terephthalate) (clay/PBT) composites films were prepared by solution casting technique. The scanning electron microscope (SEM) study showed that clay particles were well dispersed and embedded within the PBT matrix. The TGA thermograms showed that the thermal stability of PBT matrix was slightly improved by the incorporation of clay into the polymer matrix. The polarized optical microscopy (POM) study presented that the size of spherulites of PBT was decreased by the incorporation of clay into matrix, which might be due to nucleation effect of kaolin clay. The tensile strength and modulii of PBT polymer matrix were also significantly improved by the addition of clay polymer matrix. The solvent uptake study showed that the uptake of various solvents by clay/PBT nanocomposite were lower than neat PBT.
\end{abstract}

Keywords: kaolin clay, morphology, nanocomposites.

\section{Introduction}

Clay/Polymer nanocomposites exhibits some superior material properties like improved mechanical and thermal properties, gas permeability and fire retardance as compared to common neat polymers ${ }^{[1-3]}$. These superior properties of clay/polymer composite are may be due to the large surface area of clay, ionic bond between polymer and clay, and good dispersion of clay in the matrix ${ }^{[4]}$. Clay/polymer nanocomposites are commonly prepared by three principal methods, like solution intercalation, in-situ polymerization and melt intercalation ${ }^{[5-8]}$. Melt intercalation is the most convenient, versatile, compatible and environmentally favored technique for the preparation of clay/polymer composite ${ }^{[9,10]}$.

Poly(butylene terephthalate) (PBT) is an important thermoplastic polymer of polyester family. PBT is a semi crystalline engineering thermoplastic with some superior properties like high crystallization rate, chemical and thermal resistance, high impact strength, low molding temperature and excellent processing. Due to these superior properties, PBT has wide application in automotive, electronic, electric and packaging industry ${ }^{[1-14]}$. Clay/PBT nanocomposites have been studied by many researchers. Chang et al. ${ }^{[15]}$ prepared clay/PBT nanocomposites through In situ interlayer polymerization and found that the dispersion of a very small amount of organoclay can greatly enhanced thermal and mechanical properties of PBT. Xiao et al. ${ }^{[12]}$ prepared clay/PBT nanocomposite via direct melt intercalation method using thermally stable organically modified montmorillonite as filler. They also found the remarkable improvement in melting temperature and rate of crystallization of the resulted clay/PBT nanocomposites. Twin screw extrusion was also used for melt intercalation of clay/PBT nanocomposites ${ }^{[16]}$.

Kaolin was extensively used as filler for plastics and rubber. More than $60 \%$ of the word production of koalins is used in the paper industry as fillers for cellulose fibers and as coating particles in paint industry. The coating particles should be smaller than $2 \mathrm{~mm}$ and that for paper fibers being
5-7 mm. kaolin is largely used in ceramic products like porcelain, bone china, vitreous sanitary ware, earthenware, pipes, tiles and refractory bricks ${ }^{[17,18]}$.

In the present study, kaolin clay was used as filler for PBT polymer matrix. Kaolinite is the principal constituent $(85-95 \%)$ of kaolin clay. Other clay minerals of kaolin group are nacrite, dickite and are generally represented by molecular formula $\mathrm{Al}_{2} \mathrm{Si}_{2} \mathrm{O}_{5}(\mathrm{OH})_{4}^{[19]}$. Clay/PBT composite films were prepared by solution casting method in order to get a uniform of clay within the PBT matrix and then studied the effect kaolin clay on crystallization, morphology, mechanical and thermal properties of PBT.

\section{Materials and Methods}

\subsection{Materials}

PBT (average molecular weight of 38,000) and trifluroacetic acid were purchased from Sigma Aldrich and were used as received. The reinforcement material Kaolin (china clay) was kindly provided by local china clay plant Swat, Pakistan.

\subsection{Thermal treatment of kaolin clay}

Kaolin clay was dehydrated upon heating to $350{ }^{\circ} \mathrm{C}$ in the presence of oxygen. Thermal treatment below $400{ }^{\circ} \mathrm{C}$ does not lead any structural change in the clay. However, above this temperature dehydroxylation takes place which cause structural changes in kaolin ${ }^{[17]}$. To avoid these structural changes, clay is heated up to $350{ }^{\circ} \mathrm{C}$, cooled and store for further use.

\subsection{Preparation of samples}

The neat PBT and 0.5, 1, 2 wt $\%$ clay/PBT composite samples were prepared via solution casting method. The PBT was first dissolve in trifluoroacetic acid, and then added 
a known quantity of kaolin clay in the polymer solution. The mixture solution was stirred well and then sonicated for about $40 \mathrm{~min}$ in order to get homogeneous solution. The smooth dry composite films/sheets were obtained after the removal of solvent with distilled water. Similar procedure was used for the preparation of $0.5,1$ and $2 \mathrm{wt} \%$ kaolin/PBT composite films.

\subsection{Characterization}

The gold coated cryofractured surface of neat PBT and composite samples were analyzed by SEM (model JEOL JSM-5910). The POM study was performed by using POM (modal Optika B-600 POL). The samples were melted on heater, squeeze between two glass slides and then analyzed under POM. The thermal properties were studied by using TG/DTA, Perkin Elmer instrument at heating rate of $20^{\circ} \mathrm{C} / \mathrm{min}$ from room temperature to $800^{\circ} \mathrm{C}$ under nitrogen atmosphere. The mechanical properties of neat PBT and clay/PBT composites were examined using universal testing machine (UTM), Model 100-500 KN, Iestomeric Inc. The solvent uptake capacity of the samples were studied in selected solvents (distilled water, $2 \mathrm{M} \mathrm{HNO}_{3}$ solution, chloroform and kerosene oil). Small dry rectangular strips of the samples were weighed and then immersed in vials containing about $10 \mathrm{~mL}$ solvents. Percent swelling is determined by the following equation ${ }^{[20]}$.

$$
\text { Solvent uptake }(\%)=\frac{\mathrm{W}_{0}-\mathrm{W}}{\mathrm{W}} \times 100
$$

Where "W" is the weight of dry sample and "W" is the weight of wet sample in solvents.

\section{Results and Discussions}

\subsection{Morphology of clay/PBT nanocomposites}

The dispersion of fillers within the matrix has greatly affected the properties (such as thermal, mechanical, electrical properties etc.) of the matrixes. Figure 1 illustrates the SEM micrograph of fractured surface (broken in liquid nitrogen) of clay $(2 \mathrm{wt} \%) / \mathrm{PBT}$ composites film. The micrograph presented that the clay particles were not present in agglomerated but dispersed well within the PBT polymer matrix. The Figure 1 also presented that the size of the clay particles were below $800 \mathrm{~nm}$.

Figure $2 \mathrm{a}, \mathrm{b}$ show POM images of neat PBT and $2 \mathrm{wt} \%$ clay/PBT nanocomposites, respectively. Thin films of PBT and the composite were prepared by cooling both samples from the melt state. Figure 2a presented almost uniform formation of spherulites throughout the PBT matrix. The shape of neat PBT spherulites is Maltese type. The size of spherulites of neat PBT was below $25 \mu \mathrm{m}$. The POM micrograph (Figure $2 b$ ) of clay (2 wt \%)/PBT nanocomposite showed that the size of spherulites significantly decrease as compare to neat PBT. The decrease in size of spherulites in clay/PBT nanocomposite is might be due to the nucleation effect of kaolin clay. The decrease in size of spherulites in the case of nanocomposites materials were also reported by Saeed and Park, where they incorporated multi walled carbon nanotubes into polycaprolactone ${ }^{[21]}$.

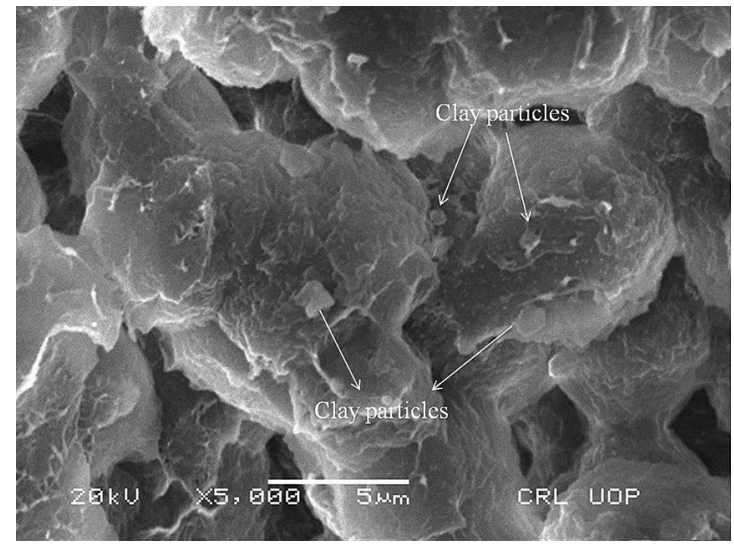

Figure 1. SEM micrographs of $2 \mathrm{wt} \%$ clay/PBT nanocomposites.
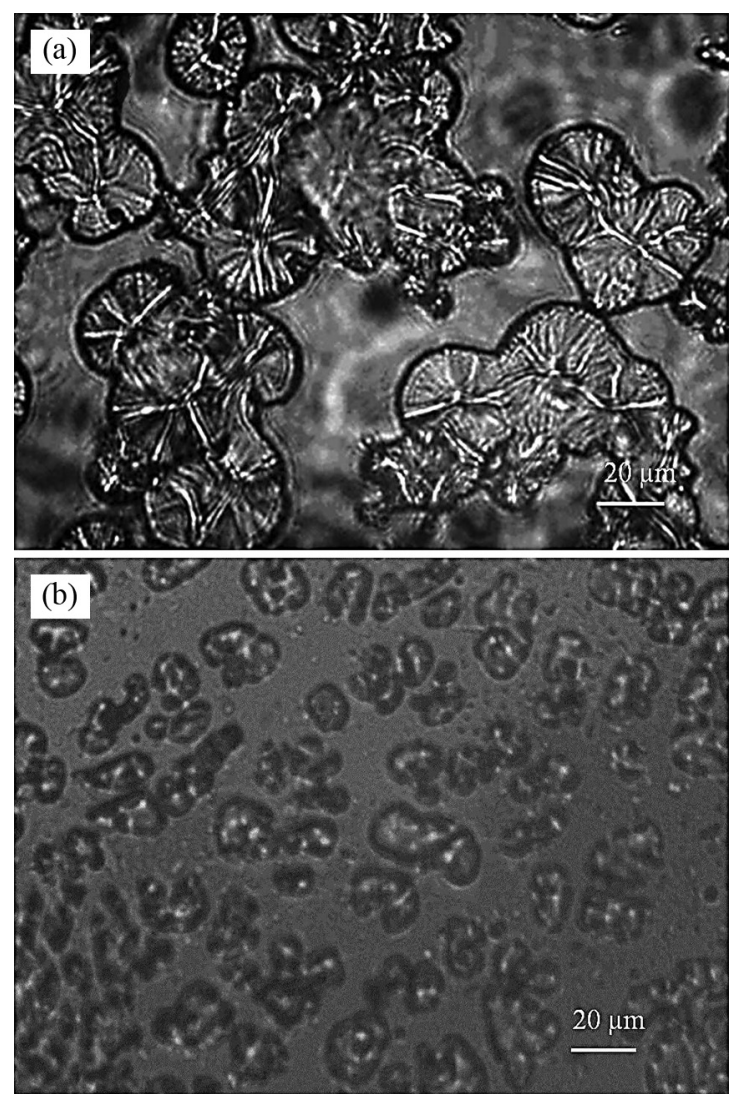

Figure 2. POM images of (a) pure PBT and (b) $2 \mathrm{wt} \%$ clay/ PBT.

\subsection{Thermal properties of neat PBT and clay/PBT nanocomposites}

TGA study was performed for the purpose to determine the effect of kaolin on the degradation temperature and thermal stability of PBT. The TGA curves of neat PBT, $0.5,1.5$ and $2 \mathrm{wt} \%$ clay/PBT nanocomposites are collectively shown in Figure 3. Figure 3 illustrated that the weight of neat PBT and nanocomposite remain unchanged till $300^{\circ} \mathrm{C}$. After $300{ }^{\circ} \mathrm{C}$, the $\mathrm{TG}$ curves starts dipping down from 300 to $450{ }^{\circ} \mathrm{C}$, which shows that the weight loss occurs in this particular range of temperature. The degradation of 
neat PBT polymer started at $300^{\circ} \mathrm{C}$ and completed at about $430^{\circ} \mathrm{C}$. While in the case of Clay/PBT nanocomposite, the degradation of compsite started at about $350^{\circ} \mathrm{C}$. It was also found that the degradation temperature of clay/PBT samples was slightly shifted to higher temperature $\left(5\right.$ to $\left.10^{\circ} \mathrm{C}\right)$. The residual quantities which contribute to the kaolin clay in the clay/PBT composite, remain at higher temperature.

Figure 4 illustrates the DTA curves for neat PBT, $0.5,1.5$ and 2 wt \% clay/PBT nanocomposite samples. All the samples have a weak endothermic peak around $200{ }^{\circ} \mathrm{C}$ and a sharp endothermic peak around $400{ }^{\circ} \mathrm{C}$ (Figure 4). The weak endothermic peak around $200{ }^{\circ} \mathrm{C}$ $\left(225^{\circ} \mathrm{C}-227^{\circ} \mathrm{C}\right)$ represents the melting, while the sharp

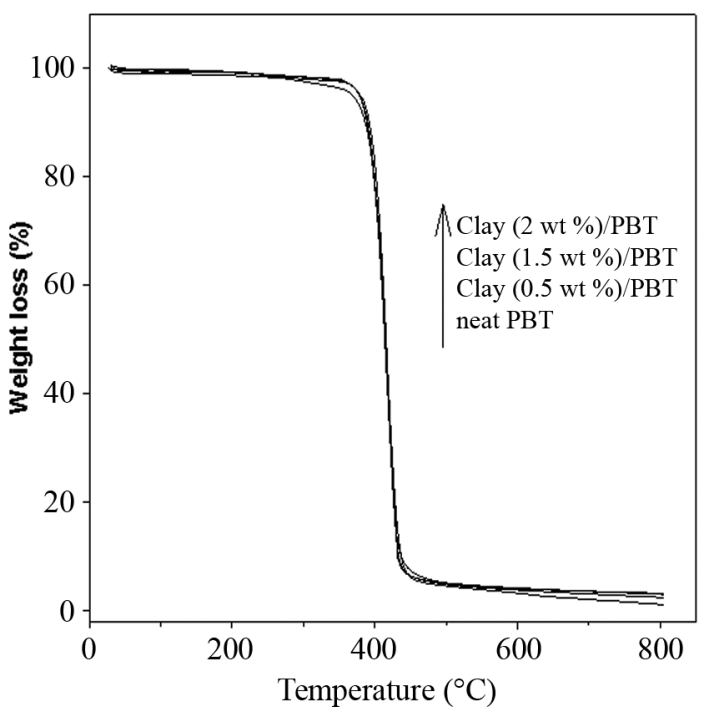

Figure 3. TGA curves of neat PBT, $0.5,1.5$ and $2 \mathrm{wt} \%$ clay/PBT nanocomposites.

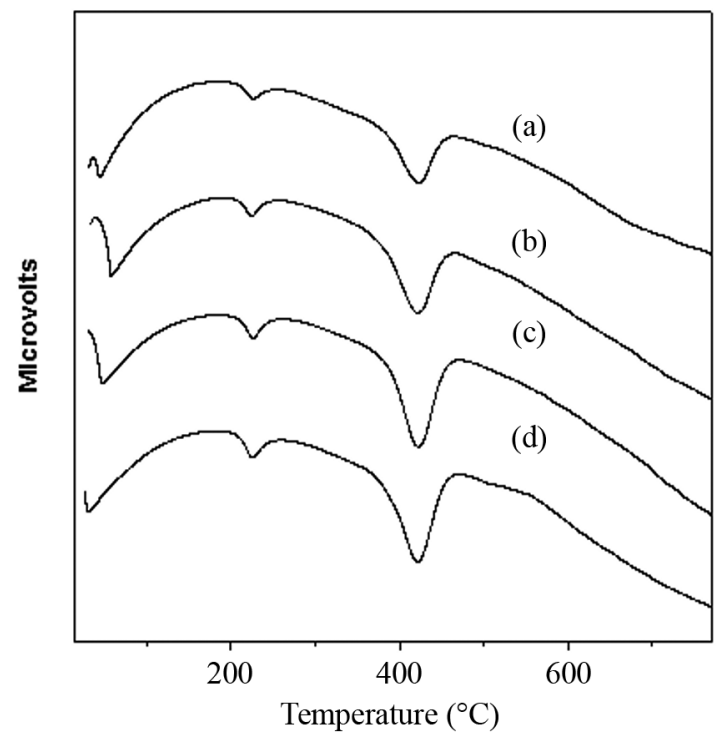

Figure 4. DTA thermographs of (a) neat PBT, (b) $0.5 \mathrm{wt} \%$, (c) $1.5 \mathrm{wt} \%$ and (d) $2 \mathrm{wt} \%$ clay/PBT nanocomposites. one around $400{ }^{\circ} \mathrm{C}$ may represent the degradation of neat $\mathrm{PBT}^{[22]}$. Multiple peaks in this region are also possible which may be due to recrystalization process ${ }^{[23]}$. As clear from Figure 4 the most noticeable difference is the height of peaks which increase gradually with increasing clay contents. The strong endothermic peaks in case of $2 \mathrm{wt} \%$ clay/PBT nanocomposites are due to the interaction between clay and polymer, which results more stable morphology through heterogeneous nucleation mechanism ${ }^{[24]}$.

\subsection{Mechanical properties of neat PBT and clay/PBT nanocomposites}

The dispersion of fillers plays a key role in improving the mechanical properties of polymeric materials. The well dispersed filler can results superior mechanical properties. Table 1 shows the mechanical properties of neat PBT, $0.5,1,1.5$ and $2 \mathrm{wt} \%$ clay/PBT nanocomposites. The increase in clay content cause a significant increase in tensile strength and modulus values as shown in Table 1 . The tensile strength values increase from $1.6 \mathrm{~N} / \mathrm{mm}^{2}$ (neat PBT) to $5.6 \mathrm{~N} / \mathrm{mm}^{2}$ ( $2 \mathrm{wt} \%$ ) while tensile modulus increase from $166.6 \mathrm{~N} / \mathrm{mm}^{2}$ (neat PBT) to $1080.9 \mathrm{~N} / \mathrm{mm}^{2}$ ( $2 \mathrm{wt} \%$ ). The results shows that both tensile strength and tensile modulus of PBT was enhanced significantly by incorporation of clay (up to $2 \mathrm{wt} \%$ ) in to the polymer matrix. Similarly, Gu et al..$^{[25]}$ also reported the improvement of mechanical properties of PET by the addition of modified montmorillonite clay.

\subsection{Solvent uptake study of neat nylon 6,6 and clay/nylon 6,6 nanocomposites}

Tables 2-4 illustrate the solvent uptake of neat PBT and clay/PBT nanocomposites. The distilled water, $2 \mathrm{M} \mathrm{HNO}_{3}$ solution, and kerosene were taken as solvents during the solvent uptake study. The results show that initially the

Table 1. Mechanical Properties of PBT and clay/PBT nanocomposites.

\begin{tabular}{ccc}
\hline Samples & $\begin{array}{c}\text { Stress Yield } \\
\left(\mathbf{N} / \mathbf{m m}^{2}\right)\end{array}$ & $\begin{array}{c}\text { Young Modulus } \\
\left(\mathbf{N} / \mathbf{m m}^{2}\right)\end{array}$ \\
\hline Neat PBT & $1.6 \pm 0.2$ & $166.6 \pm 4.37$ \\
0.5 wt \% clay/PBT & $2.2 \pm 0.1$ & $163.6 \pm 3.85$ \\
1 wt \% clay/PBT & $3.9 \pm 1.26$ & $443.9 \pm 7.5$ \\
1.5 wt \% clay/PBT & $5.6 \pm 0.04$ & $567.6 \pm 84.04$ \\
2 wt \% clay/PBT & $5.6 \pm 0.01$ & $1080.9 \pm 64.05$ \\
\hline
\end{tabular}

Table 2. Percent water uptake by neat PBT and clay/PBT composites.

\begin{tabular}{ccccc}
\hline $\begin{array}{c}\text { Time } \\
\text { (h) }\end{array}$ & PBT & $\begin{array}{c}\mathbf{0 . 5} \text { wt\% } \\
\text { clay/PBT }\end{array}$ & $\begin{array}{c}\mathbf{1 . 5} \text { wt\% } \\
\text { clay/PBT }\end{array}$ & $\begin{array}{c}\mathbf{2} \mathbf{w t} \% \\
\text { clay/PBT }\end{array}$ \\
\hline $1 / 2$ & 100.0 & 100.8 & 80 & 33.3 \\
1 & 160.0 & 150 & 100.3 & 66.7 \\
2 & 200.0 & 175 & 128 & 100.0 \\
3 & 240.0 & 210 & 140.7 & 133.3 \\
6 & 256.0 & 225 & 167.1 & 166.6 \\
12 & 280.0 & 258.3 & 200 & 200.0 \\
24 & 320.0 & 275 & 240 & 200.0 \\
48 & 328.0 & 312 & 260.1 & 233.3 \\
72 & 335.00 & 325 & 272.6 & 252 \\
\hline
\end{tabular}


Table 3. Percent kerosene uptake by neat PBT and clay/PBT composites.

\begin{tabular}{ccccc}
\hline $\begin{array}{c}\text { Time } \\
\text { (h) }\end{array}$ & PBT & $\begin{array}{c}\mathbf{0 . 5} \mathbf{w t} \% \\
\text { clay/PBT }\end{array}$ & $\begin{array}{c}\mathbf{1 . 5} \mathbf{w t} \% \\
\text { clay/PBT }\end{array}$ & $\begin{array}{c}\mathbf{2} \mathbf{w t} \% \text { clay/ } \\
\text { PBT }\end{array}$ \\
\hline $1 / 2$ & 200 & 166.6 & 150 & 140.2 \\
1 & 220 & 200 & 179 & 160 \\
2 & 240 & 233.3 & 200.8 & 172.7 \\
3 & 268 & 256.2 & 225 & 200 \\
6 & 300 & 300.0 & 241.6 & 220.3 \\
12 & 340 & 333.3 & 275.3 & 235 \\
24 & 380 & 346.6 & 305.0 & 280 \\
48 & 420 & 358.0 & 325 & 290.9 \\
72 & 430 & 361.3 & 332.7 & 303 \\
\hline
\end{tabular}

Table 4. Percent $\mathrm{HNO}_{3}$ solution uptake by neat PBT and clay/PBT composites.

\begin{tabular}{ccccc}
\hline $\begin{array}{c}\text { Time } \\
\text { (h) }\end{array}$ & PBT & $\begin{array}{c}\mathbf{0 . 5} \mathbf{w t} \% \\
\text { clay/PBT }\end{array}$ & $\begin{array}{c}\mathbf{1 . 5} \mathbf{w t} \% \\
\text { clay/PBT }\end{array}$ & $\begin{array}{c}\mathbf{2} \mathbf{w t} \% \\
\text { clay/PBT }\end{array}$ \\
\hline $1 / 2$ & 66.6 & 50 & 50 & 29.3 \\
1 & 100.0 & 70.2 & 70 & 53.6 \\
2 & 133.3 & 100 & 87.4 & 80.00 \\
3 & 150.0 & 121.4 & 110 & 133.33 \\
6 & 185.3 & 150 & 150.9 & 156.6 \\
12 & 200.0 & 175.2 & 167.2 & 176.0 \\
24 & 233.7 & 200.5 & 190 & 200.00 \\
48 & 260.2 & 215 & 210 & 200.00 \\
72 & 266.9 & 222.4 & 213.7 & 166.6 \\
\hline
\end{tabular}

solvent uptake was rapid and then the uptake of solvents slow down after $24 \mathrm{~h}$. Among the solvents, uptake of distilled water was found more rapid as compare to other kerosene and $\mathrm{HNO}_{3}$ solution. The solvent uptake of neat $\mathrm{PBT}$ and clay/PBT nanocomposites is in the following order:

Neat $\mathrm{PBT}>0.5 \mathrm{wt} \%$ clay $/ \mathrm{PBT}>1 \mathrm{wt} \%$ clay $/ \mathrm{PBT}>$ $1.5 \mathrm{wt} \%$ clay $/ \mathrm{PBT}>2 \mathrm{wt} \%$ clay/PBT

The Tables 2-4 also presented that solvent uptake decreased as the quantity of kaolin clay increased in PBT polymer matrix. This decrease in the solvent uptake with increase in concentration is might be due to some interaction between the clay and PBT, which leads to cross-linking and tortuosity in the polymer and that inhibit its solvent uptake ability.

\section{Conclusions}

The dispersion of kaolin in the PBT matrix was confirmed by SEM analysis. The neat PBT had maltase shapes spherulites. The size of PBT spherulites was highly reduced by the addition of kaolin clay. The mechanical properties of clay/PBT were significantly enhanced than neat PBT. The thermal stability of PBT was slightly improved (up to $10^{\circ} \mathrm{C}$ ) by the addition of kaolin into the polymer matrix may also be achieved. It was also found that the solvent uptake by neat PBT than the nanocomposite samples.

\section{References}

1. Agag, T., \& Takeichi, T. (2000). Polybenzoxizine-Montmorillonite Hybrid Nanocomposite synthesis and characterization.
Polymer, 41(19), 7083-7090. http://dx.doi.org/10.1016/S00323861(00)00064-1.

2. Kojima, Y., Usuki, A., Kawasumi, M., Okada, A., Fukushima, Y., Kurauchi, T., \& Kamigaito, O. (1993). Mechanical properties of nylon 6-clay hybrid. Journal of Materials Research, 8(5), 1185-1189. http://dx.doi.org/10.1557/JMR.1993.1185.

3. Usuki, A., Kojima, Y., Kawasumi, M., Okada, A., Fukushima, Y., Kurauchi, T., \& Kamigaito, O. (1993). Synthesis of nylon 6-clay hybrid. Journal of Materials Research, 8(5), 1179-1184. http://dx.doi.org/10.1557/JMR.1993.1179.

4. Wu, D., Zhou, C., Yu, W., \& Fan, X. (2005). Effect of flocculated structure on rheology of poly(butylene terephthalate)/Clay nanocomposites. Journal of Polymer Science. Part B, Polymer Physics, 43(19), 2807-2818. http://dx.doi.org/10.1002/polb.20568.

5. Ishida, H., Campbell, S., \& Blackwell, J. (2000). General approach to nanocomposite preparation. Chemistry of Materials, 12(5), 1260-1267. http://dx.doi.org/10.1021/cm990479y.

6. Messersmith, P. B., \& Giannelis, E. P. (1995). Synthesis and barrier properties of poly( $\varepsilon$-caprolactone)-layered silicate nanocomposites. Journal of Polymer Science. Part B, Polymer Physics, 33(7), 1047-1057. http://dx.doi.org/10.1002/ pola.1995.080330707.

7. Bunnak, N., Laoratanaku, P., Bhalla, A. S., \& Manuspiya, H. (2013). Dielectric properties improvement of polymer composite prepared from poly(vinylidene difluoride) and barium-modified porous clay heterostructure. Electronic Materials Letters, 9(3), 315-323. http://dx.doi.org/10.1007/s13391-012-2210-z.

8. Ahmadi, S. J., Huang, Y. D., \& Li, W. (2004). Review synthetic routes, properties and future applications of polymer-layered silicate nanocomposites. Journal of Materials Science, 39(6), 19191925. http://dx.doi.org/10.1023/B:JMSC.0000017753.90222.96.

9. Sinha Ray, S., \& Okamoto, M. (2003). Polymer/layered silicate nanocomposites: a review from preparation to processing. Progress in Polymer Science, 28(11), 1539-1641. http://dx.doi. org/10.1016/j.progpolymsci.2003.08.002

10. Li, X. C., Kang, T. Y., Cho, W. J., Lee, J. K., \& Ha, C. S. (2001). Preparation and characterization of poly(butyleneterephthalate)/ organoclay nanocomposites. Macromolecular Rapid Communications, 22(16), 1306-1312. http://dx.doi.org/10.1002/15213927(20011101)22:16<1306::AID-MARC1306>3.0.CO;2-I.

11. Weichenhain, R., Wesner, D. A., Pfleging, W., Horn, H., \& Kreutz, E. W. (1997). KrF-excimer laser pretreatment and metallization of polymers. Applied Surface Science, 109-110, 264-269. http://dx.doi.org/10.1016/S0169-4332(96)00910-5.

12. Xiao, J. F., Hu, Y. A., Lu, H. D., Cai, Y. B., Chen, Z. Y. J., \& Fan, W. (2007). Effect of order of mixing on morphology and thermal properties of the compatibilized PBT and ABS alloys/ OMT nanocomposites. Journal of Applied Polymer Science, 104(4), 2130-2139. http://dx.doi.org/10.1002/app.24218.

13. Canto, L. B., Hage, E., \& Pessan, L. A. (2006). Effects of the molecular structure of impact modifier and compatibilizer on the toughening of PBT/SBS/PS-GMA blends. Journal of Applied Polymer Science, 102(6), 5795-5807. http://dx.doi. org/10.1002/app.24721.

14. Larocca, N. M., Hage E. \& Pessan, L. A. (2004). Toughening of poly(butylene terephthalate) by AES terpolymer. Polymer, 45(15), 5265-5277 http://dx.doi.org/10.1016/j.polymer.2004.05.056

15. Chang, J. H., An, Y. U., Kim, S. J., \& Im, S. S. (2003). Poly(butylene terephthalate)/organoclay nanocomposites prepared by in situ interlayer polymerization and its fiber (II). Polymer, 44(19), 5655-5661. http://dx.doi.org/10.1016/ S0032-3861(03)00613-X.

16. Chang, Y. W., Kim, S. S., \& Kyung, Y. B. (2005). Poly(butylene terephthalate)-clay nanocomposites prepared by melt intercalation: morphology and thermomechanical properties. 
Polymer International, 54(2), 348-353. http://dx.doi.org/10.1002/ pi.1686.

17. Jepson, W. B. (1984). Kaolins: their properties and uses. Philosophical Transactions of the Royal Society of London. Series A, Mathematical and Physical Sciences, 311(1517), 411-432. http://dx.doi.org/10.1098/rsta.1984.0037.

18. Murray, H. H. (2000). Traditional and new applications for kaolin, smectite, and palygorskite: a general overview. Applied Clay Science, 17(5-6), 207-221. http://dx.doi.org/10.1016/ S0169-1317(00)00016-8.

19. Grim, R. E. (1968). Clay mineralogy. New York: McGraw-Hill.

20. Haider, S., Park, S. Y., Saeed, K., \& Farmer, B. L. (2007). Swelling and electroresponsive characteristics of gelatin immobilized onto multi-walled carbon nanotubes. Sensors and Actuators. B, Chemical, 124(2), 517-528. http://dx.doi. org/10.1016/j.snb.2007.01.024.

21. Saeed, K., \& Park, S.-Y. (2007). Preparation and properties of multiwalled carbon nanotube/polycaprolactone nanocomposites. Journal of Applied Polymer Science, 104(3), 1957-1963. http:// dx.doi.org/10.1002/app.25902.

22. Shyang, C. W. (2008). Tensile and thermal properties of poly(Butylene Terephtalate)/organo-montmorillonite. Malaysian
Polymer Journal, 3(1), 1-13. Retrieved in 16 November 2015, from http://www.cheme.utm.my/mpj/images/080301_1chow. pdf

23. Xiao, J. F., Hu, Y., Wang, Z. Z., Tang, Y., Chen, Z. Y., \& Fan, W. C. (2005). Preparation and characterization of poly(butylene terephthalate) nanocomposites from thermally stable organicmodified montmorillonite. European Polymer Journal, 41(5), 1030-1035. http://dx.doi.org/10.1016/j.eurpolymj.2004.11.025.

24. Venkataramani, S., Lee, J. H., Park, M. G., \& Kim, S. C. (2009). Structure and properties of polyamide- 6 \& 6/66 clay nanocomposites. Journal of Macromolecular Science, Part A: Pure and Applied Chemistry, 46(1), 65-73. http://dx.doi. org/10.1080/10601320802515399.

25. Gu, X. H., Zeng, P., Zhou, J. L., \& Xu, B. (2014). Preparation and characterization of poly(ethylene terephthalate) incoporated with secondary-modified montmorillonite. Iranain Polymer Journal, 23(4), 249-255.

Received: Feb. 03, 2014

Revised: July 27, 2015

Accepted: Aug. 11, 2015 